\title{
Dynamics of Health Technology Diffusion in the Integrated Care System (DHTDICS): A Development and Validation Study in China
}

This article was published in the following Dove Press journal: Risk Management and Healthcare Policy

\section{Qingwen Deng \\ Junhong Lu \\ Zhichao Zeng \\ Yuhang Zheng (D) \\ Wenbin Liu}

Department of Health Management, School of Public Health, Fujian Medical University, Fuzhou 350122, People's Republic of China
Correspondence: Wenbin Liu Department of Health Management, School of Public Health, Fujian Medical University, Room 108 in the Building for School of Public Health, No. I Xuefubei Road, Minhou District, Fuzhou 350I22,

People's Republic of China

Tel + 8613799983766

Email wenbinliu 126@I26.com
Background: Limited diffusion of health technology has greatly halted the improvement of resource integration and healthcare outcomes. The importance of understanding the dynamics of health technology diffusion is increasingly highlighted. However, the dynamic mechanism of health technology diffusion in the context of the integrated care system (ICS) remained largely unknown.

Purpose: To develop and validate the scale on Dynamics of Health Technology Diffusion in Integrated Care System (DHTDICS) for providing an instrument to investigate the health technology diffusion in the ICS in China, by taking the Des-gamma-Carboxy Prothrombin (DCP) test as an example.

Methods: Based on previous classical theories such as the theory of planned behavior (TPB), technology acceptance model (TAM), and technology-organization-environment framework (TOE), the scale with 34 items was initially developed. It was tested in a crosssectional questionnaire survey including 246 participants from February to August 2019 in China. Cronbach's alpha, corrected item-total correlation, and factor loadings were used to assess reliability. Exploratory factor analysis and confirmatory factor analysis were applied to evaluate the validity by assessing factor structures and correlations.

Results: Reliability analysis revealed excellent internal consistency. Acceptable validity was confirmed through tests of convergent validity and discriminant validity. Regarding the domains that DHTDICS contributes, the results highlighted 4 domains: personal beliefs (including dimensions of attitudes, subjective norms and perceived behavioral control), technical drivers (including dimensions of ease of use and price rationality), organizational readiness (including dimensions of organizational culture, technology absorptive willingness and technology sharing willingness), and external environment (dimension of industry competition pressure).

Conclusion: The findings confirmed the reliability and validity of the scale on DHTDICS. The scale will be not only a scientific tool in determining the dynamics of health technology diffusion in the ICS, but also a helpful reference for developing future interventions to promote health technology diffusion.

Keywords: health technology diffusion, dynamics, scale development, integrated care system, validity, reliability, China

\section{Introduction}

Integrated care system (ICS) can be defined as a health system that integrates the inputs, delivery, management of various health care services, including health promotion, disease prevention, treatment and rehabilitation. ${ }^{1}$ As the importance of 
ICS becoming increasingly highlighted, its growth is accelerating worldwide with various forms of practice. ${ }^{2-4}$ For instance, in England, primary care trusts (PCTs) are free-standing bodies to integrate community health services and social services. In America, patient-centered medical home (PCMH) is a model of care in which patients receive integrated care from their designated providers. And in the Netherlands, people-centered and integrated health care services (PCIHC) is to restructure the health service network that composed of interconnected providers at all levels. Similar to these forms, China's regional medical consortium (RMC) is expressed in terms of national conditions under the connotation of ICS. RMC is an important means of integrating medical resources in China, which mainly involves local or crossregional leading hospitals, as well as other health institutions with a lower level. ${ }^{5}$ The most common collaboration between participants in RMC is technical assistance, which is characterized as providing technical cooperation or support to each other. This collaboration model benefits promoting communication and collaboration between different levels of health institutions, ${ }^{6,7}$ as well as puts forward higher requirements on the integration ability of health resources and the service quality. ${ }^{8,9}$

Although some achievements have been made in the integration of health resources in the RMC, the problem of under-utilization of health technology still exists in practice, and the value of many health technologies has not been given full play. ${ }^{10}$ Des-gamma-Carboxy Prothrombin (DCP) for example, is a tumor marker of primary hepatocellular carcinoma (PHCC), and the security, effectiveness and economy of DCP test in early detection of PHCC have been reported in many clinical practices and studies. ${ }^{11-14}$ In addition to large hospitals, ${ }^{15,16}$ the role of DCP implementation has also been verified in county hospitals or other health institutions with a lower level in China. ${ }^{17}$ However, in terms of coverage even in the context of RMC, the use of DCP in China is far behind Japan, which also has a high incidence of liver cancer but with DCP widely and routinely used to screen for liver cancer. $^{18}$

To further address the problem in the practice of technology diffusion, many theories were applied to define the connotation of technology diffusion. And its facilitators and barriers were also investigated in a large number of studies in the disciplines of sociology, behavior, psychology, and so on. ${ }^{19-21}$ The interpretations of technology diffusion vary depending on the disciplines. According to the Innovation Diffusion Theory (IDT) proposed by Rogers, ${ }^{22}$ this study defines technology diffusion as the process in which technology is communicated between and within organizations of a social system. In addition to the IDT, many other classical theories have been proposed to guide the adoption practices by exploring the effects of different sets of factors on technology diffusion, such as the Theory of Planned Behavior (TPB), Technology Acceptance Model (TAM), and TechnologyOrganization-Environment framework (TOE). Among these theories, TPB suggests an individual's behavior is ultimately influenced by behavioral intention, which is a function of attitude toward behavior, subjective norms, and perception of the ease with the behavior that can be performed. $^{23}$ TAM implies perceived usefulness and perceived ease of use as two crucial factors, which focuses on the impact of technology natures. ${ }^{24}$ IDT demonstrates that the properties of technology and interpersonal communication can affect technology use. ${ }^{25}$ TOE infers that the effect of technology, organization and external environment should be considered. ${ }^{26}$

Despite previous theories mostly focused on some stages of technology diffusion and investigate certain sets of potential domains, there were still insufficient explanations in terms of the dynamic mechanism of health technology diffusion from different perspectives and facets. Therefore, by taking the DCP test as an example, this study aims to integrate these theories to provide a comprehensive insight into the health technology diffusion, to develop and validate an instrument for measuring and further investigating the dynamics of health technology diffusion in the ICS.

\section{Materials and Methods Theoretical Model}

Based on the theories mentioned above, we integrated some core elements and proposed a theoretical model for the dynamics of health technology diffusion in the ICS from four domains, namely the domain of personal beliefs, technical drivers, organizational readiness, and external environment (Figure 1).

In this study, personal beliefs referred to the physicians' perceptions of the DCP test and its use, which mainly depend upon attitudes, subjective norms, and perceived behavioral control. ${ }^{27,28}$ Attitude has been perceived as one of the most powerful predictors in technology adoption and use, while subjective norms are kind of 


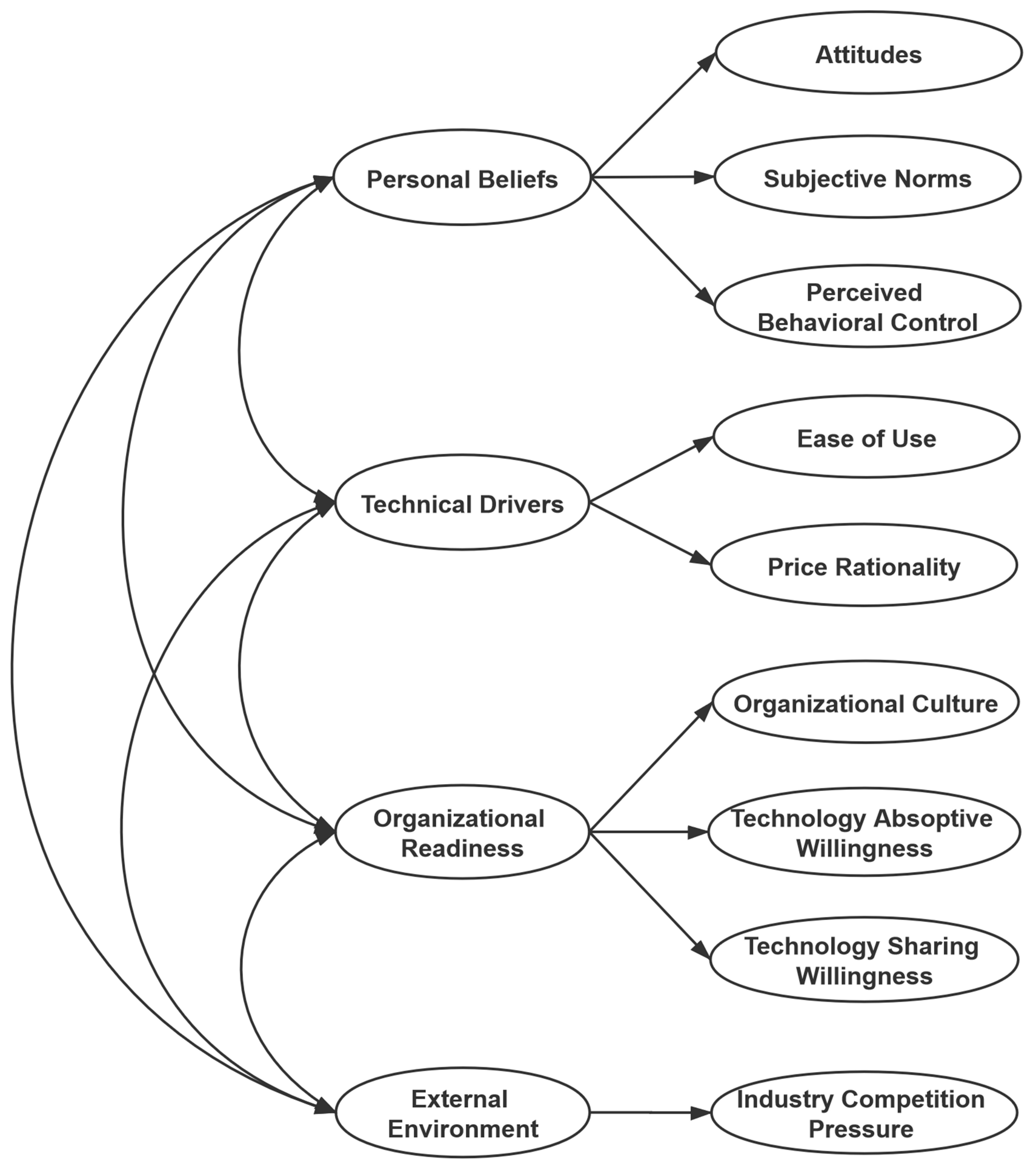

Figure I The model of the dynamics of health technology diffusion in ICS.

Note: Double-headed arrows represent correlations between variables and single-headed arrows represent regression relationships between variables.

perceived criteria and pressures from important individuals' judgments. And perceived behavioral control is often based on beliefs concerning access to the necessary resources and opportunities to successfully perform a behavior.
The technical drivers involved the nature of technology including ease of use and price rationality. Taking the DCP test for instance, ease of use is a degree to which the physicians expect the DCP test can be performed with ease, while price rationality is an underlying important 
source of motivation. ${ }^{29,30}$ People are tending to adopt technologies easier to perform with price rationality.

Moreover, studies have mentioned the importance of organizational readiness, which reflects the overall preparedness for health technology of the entire staff. ${ }^{31}$ It consisted of organizational culture, technology absorptive willingness, and technology sharing willingness. Organizational culture is the ensemble of values, norms, and operating behaviors shared by members within an organization. $^{32,33}$ Technology absorptive willingness shows the willingness and readiness situations of introducing a new health technology into the organization, ${ }^{34}$ while technology sharing willingness is a degree of sharing knowledge with the other organizations. ${ }^{35,36}$

The domain of external environment is generally considered as an important factor affecting health technology diffusion, which usually focuses on industry competition pressure. $^{37,38}$ Both the trend in the market and the tendency of business partners are the main concerns of the hospital managers while deciding on whether to adopt certain technology. ${ }^{39}$

\section{Measurement}

According to the proposed model in Figure 1, the scale of Dynamics of Health Technology Diffusion in Integrated Care System (DHTDICS) was initially structured with 2 parts, 34 items (see supplementary file).

The first part with 28 items was the measurement of the components of DHTDICS, which consists of 9 dimensions in 4 domains: personal beliefs, including dimensions of "attitudes" (ATT), "subjective norms" (SN) and "perceived behavioral control" (PBC); technical drivers, including dimensions of "ease of use" (EOU) and "price rationality" (PR); organizational readiness, including dimensions of "organizational culture" (OC), "technology absorptive willingness" (TAW) and "technology sharing willingness" (TSW); external environment, namely "industry competition pressure" (ICP). All 28 items were measured using a 5-point Likert scale ranging from "strongly disagree" (1) through "neutral" (3) to "strongly agree" (5).

The second part of the questionnaire was used to collect personal socio-demographic characteristics of respondents (physicians), including 8 items of gender, age, education, professional title, administration position, years in practice, the RMC, and the level of the medical institution. Age was recoded into three groups: $<35$ years old (1), 35 44 years old (2), and $\geq 45$ years old (3).
Education was divided into junior college or below (1), bachelor (2), master (3), and doctor (4). The professional title of physicians included three levels: junior (1), intermediate (2), and senior (3). If a physician has a concurrent management position, he/she is considered to have an administration position (1); otherwise, he/she had no administration position (2). Years in practice were classified into five groups: $<5$ years (1), 15 10 years (2), 11 15 years (3), 16 20 years (4), and $>20$ years (5). The level of the medical institution included secondary or bellow (1) and tertiary (2).

\section{Sample and Procedure}

To validate the scale developed in this study, a crosssectional questionnaire survey was conducted from February to August 2019 using a multistage random sampling method. Firstly, based on the latest average incidence of liver cancer in China $(26.92 / 100,000),{ }^{40}$ Fujian and Jiangxi provinces were randomly selected from the provinces with a high and low incidence of hepatocellular carcinoma, respectively (the incidence of liver cancer in Fujian and Jiangxi were 32.18/100,000 and $23.80 / 100,000$, respectively ${ }^{41,42}$ ). Secondly, we listed all RMCs in each province as sampling frame, and two RMCs were randomly selected from each province. Thirdly, a sampling frame was made to list all medical institutions of four RMCs, and $50 \%$ of the medical institutions within each RMC were randomly selected to be included in the survey. Finally, the scales were distributed to the physicians who had knowledge of DCP and worked in liver disease-related departments in these medical institutions (including the department of hepatology, oncology, gastroenterology, infection, ultrasound, etc.). With the support of selected medical institutions, each round for filling out the questionnaire was accompanied by a trained coordinator to introduce the study purpose. All responses were anonymous, but participants were invited to submit their contact information if they were interested in this study or wanted to be kept informed of the study results.

Each RMC was expected to investigate $5 \sim 8$ medical institutions, and four RMCs in two provinces would include 20 30 medical institutions. Each medical institution would investigate 10 20 physicians on average, and at least a total of 200 physicians would participate in the survey, which met the sample size requirement that at least 5 times of the survey question. ${ }^{43}$ 


\section{Data Analysis}

Instrument optimization was in virtue of the corrected item-total correlation (CITC) and the Cronbach's alpha if item deleted. Items would be deleted if their results satisfy both of two conditions: 1) the CITC less than $0.6 ; 2$ ) Cronbach's alpha would be improved if this item was deleted. ${ }^{44}$ Besides, there was a need to ensure that at least three items per factor were used in order to interpret the results.

Reliability analysis was conducted by calculating Cronbach's alpha, CITC and factor loadings. Generally, internal consistency is adequate if the following criteria were met: 1) Cronbach's alpha $>0.7$; 2) CITC $>0.6 ; 3$ ) factor loadings $>0.5 .{ }^{45,46}$

The validity was initially examined with exploratory factor analysis (EFA), which can explore the possible factors and factor structure in the pool of items by principal components analysis (PCA) (the method of factor extraction). Kaiser-Meyer-Olkin (KMO) value, Bartlett's test of sphericity, eigenvalues, factor matrix, and correlation matrix were used to verify the factorability. The recommended threshold of the KMO value is $0.7 .{ }^{47}$ Factors with eigenvalues greater than 1 in the factor extraction were determined. Confirmatory factor analysis (CFA) was used to further test convergent validity and discriminant validity by structural equation modeling (SEM), including indicators of the average variance extracted (AVE), composite reliability (CR), and the root of AVE. The criteria commonly used are: 1) AVE > 0.5;2) $\mathrm{CR}>0.7$; 3) the root of AVE $>0.7$, and higher than the correlation with other factors. ${ }^{48,49}$

Data analyses were performed using IBM SPSS software 20.0 version (SPSS, Inc., Chicago, IL, USA) and Amos 17.1 software. Statistical significance was set at $P<0.05$.

\section{Results}

\section{Sample and Data Description}

This study included a total of 246 physicians in 23 medical institutions in 4 RMCs. The corresponding sample-to-item ratio of 9.84 was greater than the threshold of 5 [40], it can be considered that sample sizes collected were acceptable. Table 1 demonstrates the demographic characteristics of the 246 participants. Among the participants, $66.26 \%$ were males and $33.74 \%$ were females. Over eighty percent $(83.74 \%)$ were in the age group of under 45 years old. In terms of educational level, $90.65 \%$ reported having a bachelor's degree or above. The majority of participants had obtained junior $(35.37 \%)$ or intermediate $(36.99 \%)$ professional titles. Most of the participants (79.27\%) had no administration position. The participants who had 5 10 years in practice accounted for $30.08 \%$, followed by $11 \sim 15$ years in practice $(29.27 \%$ ). About $66.26 \%$ of the participants were from Fujian province, and $33.74 \%$ were from Jiangxi province. The majority of participants were in tertiary hospitals $(62.60 \%)$, and the RMC type of most participants was specialist RMC (64.23\%).

Data on each domain are shown in Table 2. In the domain of personal beliefs, more than $70 \%$ of the participants agreed (selected "agree" or "strongly agree") with the description of each item. The proportion of disagreement (selected "disagree" or "strongly disagree") ranged from $2.03 \%$ to $6.91 \%$ for each item. In the domain of technical drivers, for each item, the percentage indicating agreement ranged from $48.37 \%$ to $67.88 \%$. In the domain of organizational readiness, about $6.51 \%$ to $13.42 \%$ of the participants showed their disagreement over the description of the item. In the domain of external environment, more than a quarter of the participants were neutral in each item.

\section{Items Optimization}

As demonstrated in Table 3, all CITC values of items were greater than the ideal value of 0.6, and Cronbach's alpha of the factor cannot be improved despite the item deleted. Therefore, no item needs to be eliminated from the instrument.

\section{Instrument Reliability}

Table 3 shows the Cronbach's alpha of all factors and the whole questionnaire are much higher than the recommended threshold of 0.7. Also, all CITC values and factor loadings of each item were above the acceptability value of 0.5 , suggesting the internal consistency of the questionnaire was fairly well.

\section{Instrument Validity Exploratory Factor Analysis}

A PCA of all the 28 items showed KMO values of 0.920 and Bartlett's test of sphericity was strongly significant $(P<0.001)$, indicating the great suitability of PCA for validity estimate. Four factors appeared with an eigenvalue greater than 1 and cumulatively explained $76.36 \%$ of the total variance. To further defined factors included clearly, the varimax rotation method was then used. 
Table I Demographic Characteristics of the 246 Participants

\begin{tabular}{|c|c|c|c|}
\hline Variables & Categories & $\begin{array}{l}\text { Frequency } \\
\text { (n) }\end{array}$ & $\begin{array}{l}\text { Percentage } \\
\text { (\%) }\end{array}$ \\
\hline \multirow[t]{2}{*}{ Gender } & Male & 163 & 66.26 \\
\hline & Female & 83 & 33.74 \\
\hline \multirow[t]{3}{*}{ Age } & $<35$ years old & 107 & 43.50 \\
\hline & $\begin{array}{l}35 \sim 44 \text { years } \\
\text { old }\end{array}$ & 99 & 40.24 \\
\hline & $\geq 45$ years old & 40 & 16.26 \\
\hline \multirow[t]{4}{*}{ Education } & $\begin{array}{l}\text { Junior college } \\
\text { or below }\end{array}$ & 23 & 9.35 \\
\hline & Bachelor & 140 & 56.91 \\
\hline & Master & 76 & 30.89 \\
\hline & Doctor & 7 & 2.85 \\
\hline \multirow[t]{3}{*}{ Professional title } & Junior & 87 & 35.37 \\
\hline & Intermediate & 91 & 36.99 \\
\hline & Senior & 68 & 27.64 \\
\hline \multirow{2}{*}{$\begin{array}{l}\text { Administration } \\
\text { position }\end{array}$} & Yes & 51 & 20.73 \\
\hline & No & 195 & 79.27 \\
\hline \multirow[t]{5}{*}{ Years in practice } & $<5$ years & 62 & 25.20 \\
\hline & $5 \sim 10$ years & 74 & 30.08 \\
\hline & $11 \sim 15$ years & 72 & 29.27 \\
\hline & $16 \sim 20$ years & 33 & $|3.4|$ \\
\hline & $>20$ years & 5 & 2.04 \\
\hline \multirow[t]{2}{*}{ Province } & Fujian & 163 & 66.26 \\
\hline & Jiangxi & 83 & 33.74 \\
\hline \multirow[t]{2}{*}{ Type of RMC } & Urban RMC & 88 & 35.77 \\
\hline & $\begin{array}{l}\text { Specialist } \\
\text { RMC }\end{array}$ & 158 & 64.23 \\
\hline \multirow[t]{2}{*}{$\begin{array}{l}\text { Level of the } \\
\text { medical institution }\end{array}$} & $\begin{array}{l}\text { Secondary or } \\
\text { below }\end{array}$ & 92 & 37.40 \\
\hline & Tertiary & 154 & 62.60 \\
\hline
\end{tabular}

Abbreviation: RMC, regional medical consortium.

Table 4 shows all items in each dimension are almost loaded to four different factors, which fits well with the proposed framework and indicates acceptable construct validity. Factor 1 to factor 4 explained 26.34\%, 24.32\%, $14.42 \%$, and $11.28 \%$ of the total variance, respectively. Accordingly, we named factor 1 as "personal beliefs", factor 2 as "organizational readiness", factor 3 as "technical drivers", and factor 4 as "external environment", respectively. Besides, factor scores of the four factors were automatically generated into the last columns of the operation interface.

Meanwhile, we show the correlations between the items and factor scores of each factor. The results are shown in Table 5. Each of the factors was separated from each other on account of having a low correlation with each other. Additionally, items of the same dimension converged on the same factor and discriminated well with other factors.

\section{Confirmatory Factor Analysis}

To further validate the research model, we calculated indicators of AVE and CR for each factor through the SEM approach to assessing convergent validity. The results showed that AVE and CR values of all factors were, respectively, above the recommended value of 0.5 and 0.7 (Table 3), which indicates a good convergent validity.

Then, we followed Fornel and Larcker's (1981) suggestion to calculate the square root of AVE to reflect the discriminant validity. ${ }^{47}$ As shown in Table 6, the square root of AVE (reported in the diagonal of the correlation matrix) of each factor is higher than its correlation coefficients with other factors, indicating its strong discriminant validity.

\section{Discussion}

The diffusion and utilization of many innovative appropriate health technologies (such as DCP test) are limited. ${ }^{50-52}$ These health technologies are currently only being implemented in some medical institutions (such as large urban hospitals) and some populations, ${ }^{53}$ and their value in preventing disease and improving health has not been fully realized. ${ }^{54,55}$ Meanwhile, it also leads to the confusion of functional positioning among medical institutions and the poor effect of health resource integration, ${ }^{56}$ that is, the screening function which was originally in charge of primary health care institutions is transferred to large hospitals. This issue has become even more severe and prominent especially under the background of continuous ICS growth worldwide. To bridge the research gap that few is known on the dynamic mechanism of health technology diffusion in the ICS, this study took the DCP test as an example and developed an instrument to measure and evaluate the dynamics of health technology diffusion in the integrated care system (DHTDICS). It will be 
Table 2 Items of Perceptions on DCP and Its Diffusion

\begin{tabular}{|c|c|c|c|c|c|}
\hline \multirow[t]{2}{*}{ Items of Each Domain } & \multicolumn{5}{|c|}{ Frequency (\%) } \\
\hline & $\begin{array}{l}\text { Strongly } \\
\text { Disagree }\end{array}$ & Disagree & Neutral & Agree & $\begin{array}{l}\text { Strongly } \\
\text { Agree }\end{array}$ \\
\hline \multicolumn{6}{|l|}{ Personal beliefs } \\
\hline $\begin{array}{l}\text { ATTI. I think it's a right thing to use DCP for early diagnosis of } \\
\text { hepatocellular carcinoma }\end{array}$ & $0(0)$ & $6(2.44)$ & $51(20.73)$ & $83(33.74)$ & $106(43.09)$ \\
\hline $\begin{array}{l}\text { ATT2. I think it's a wise choice to use DCP for early diagnosis of } \\
\text { hepatocellular carcinoma }\end{array}$ & $\mathrm{I}(0.4 \mathrm{I})$ & $9(3.66)$ & $48(|9.5|)$ & $83(33.74)$ & $105(42.68)$ \\
\hline $\begin{array}{l}\text { ATT3. I think it's good for all to use DCP for early diagnosis of } \\
\text { hepatocellular carcinoma }\end{array}$ & $0(0)$ & $7(2.86)$ & $47(19.11)$ & $81(32.93)$ & III (45.12) \\
\hline $\begin{array}{l}\text { SNI. People who are important to me tend to use DCP for early diagnosis } \\
\text { of hepatocellular carcinoma }\end{array}$ & $4(1.63)$ & $12(4.88)$ & $52(21.14)$ & $74(30.08)$ & $104(42.27)$ \\
\hline $\begin{array}{l}\text { SN2. People who are important to me have a positive attitude on using } \\
\text { DCP for early diagnosis of hepatocellular carcinoma. }\end{array}$ & $5(2.03)$ & $12(4.88)$ & $53(21.54)$ & $70(28.46)$ & $106(43.09)$ \\
\hline $\begin{array}{l}\text { SN3. People who are important to me think it's a right thing to use DCP } \\
\text { for early diagnosis of hepatocellular carcinoma. }\end{array}$ & $I(0.4 I)$ & $10(4.07)$ & $57(23.17)$ & $71(28.85)$ & $107(43.50)$ \\
\hline $\begin{array}{l}\mathrm{PBCl} \text {. Using } \mathrm{DCP} \text { can make me have more choice in diagnosing liver } \\
\text { cancer. }\end{array}$ & $\mathrm{I}(0.4 \mathrm{I})$ & $7(2.85)$ & $43(17.48)$ & $78(31.7 I)$ & $117(47.56)$ \\
\hline PBC2. Using DCP can increase my confidence in diagnosing liver cancer. & $0(0)$ & $5(2.03)$ & $46(18.70)$ & $80(32.52)$ & $115(46.75)$ \\
\hline PBC3. Using DCP can make my diagnosis more recognized. & $0(0)$ & $5(2.03)$ & $47(19.11)$ & $80(32.52)$ & $114(46.34)$ \\
\hline \multicolumn{6}{|l|}{ Technical drivers } \\
\hline $\begin{array}{l}\text { EOUI. We can easily obtain the materials and instruments needed for } \\
\text { DCP test }\end{array}$ & $5(2.03)$ & II (4.47) & 75 (30.49) & $68(27.64)$ & $87(35.37)$ \\
\hline EOU2. We can get the result of DCP test in a short time after detection & $0(0)$ & $7(2.85)$ & $72(29.27)$ & $77(31.30)$ & $90(36.58)$ \\
\hline $\begin{array}{l}\text { EOU3. We can be provided with assistance in clinical diagnosis by the } \\
\text { result of DCP test }\end{array}$ & $0(0)$ & $6(2.44)$ & $53(21.54)$ & $82(33.33)$ & $105(42.69)$ \\
\hline $\begin{array}{l}\text { PRI. Compared with the same type of serological tests, the price of DCP } \\
\text { is relatively cheaper }\end{array}$ & $7(2.85)$ & $12(4.88)$ & $108(43.90)$ & $57(23.17)$ & $62(25.20)$ \\
\hline PR2. DCP test has a high cost performance & $3(1.22)$ & $9(3.66)$ & $92(37.40)$ & $71(28.86)$ & $71(28.86)$ \\
\hline PR3. The price of DCP is affordable for most patients & $4(1.63)$ & $5(2.03)$ & $79(32.11)$ & $70(28.46)$ & $88(35.77)$ \\
\hline \multicolumn{6}{|l|}{ Organizational readiness } \\
\hline $\begin{array}{l}\text { OCI. The hospital advocates the technical innovation to improve the } \\
\text { clinical outcomes for patients. }\end{array}$ & $15(6.10)$ & $12(4.88)$ & $51(20.73)$ & $79(32.11)$ & $89(36.18)$ \\
\hline $\begin{array}{l}\text { OC2. The hospital advocates continuous learning and absorption of new } \\
\text { technologies }\end{array}$ & $10(4.07)$ & $6(2.44)$ & $44(17.88)$ & $79(32.11)$ & $107(43.50)$ \\
\hline $\begin{array}{l}\text { OC3. The hospital advocates the exchange and sharing of clinical } \\
\text { experience }\end{array}$ & $10(4.07)$ & $6(2.44)$ & $48(19.5 \mathrm{I})$ & $76(30.89)$ & $106(43.09)$ \\
\hline $\begin{array}{l}\text { TAWI. When DCP test appeared, the hospital is willing to allocate } \\
\text { relevant staff to collect information }\end{array}$ & $15(6.10)$ & $14(5.69)$ & $70(28.46)$ & $71(28.86)$ & $76(30.89)$ \\
\hline
\end{tabular}


Table 2 (Continued).

\begin{tabular}{|c|c|c|c|c|c|}
\hline \multirow[t]{2}{*}{ Items of Each Domain } & \multicolumn{5}{|c|}{ Frequency (\%) } \\
\hline & $\begin{array}{l}\text { Strongly } \\
\text { Disagree }\end{array}$ & Disagree & Neutral & Agree & $\begin{array}{l}\text { Strongly } \\
\text { Agree }\end{array}$ \\
\hline $\begin{array}{l}\text { TAW2. When DCP test introduced, the hospital is willing to provide } \\
\text { training for the staff }\end{array}$ & $24(9.76)$ & $9(3.66)$ & $68(27.64)$ & $75(30.48)$ & $70(28.46)$ \\
\hline $\begin{array}{l}\text { TAW3. When DCP test adopted for clinical practice, the hospital is willing } \\
\text { to promote its use more widely }\end{array}$ & $22(8.94)$ & II (4.47) & $73(29.68)$ & $72(29.27)$ & $68(27.64)$ \\
\hline $\begin{array}{l}\text { TSWI. The hospital is willing to send the information of DCP test with } \\
\text { other institutions }\end{array}$ & $10(4.07)$ & $9(3.66)$ & $51(20.73)$ & $80(32.52)$ & $96(39.02)$ \\
\hline $\begin{array}{l}\text { TSW2. The hospital is willing to discuss the problems of DCP use with } \\
\text { other institutions }\end{array}$ & $9(3.66)$ & $8(3.25)$ & $52(21.14)$ & $82(33.33)$ & $95(38.62)$ \\
\hline $\begin{array}{l}\text { TSW3. The hospital is willing to share the experience of DCP use with } \\
\text { other institutions }\end{array}$ & $10(4.07)$ & $7(2.85)$ & $46(18.70)$ & $87(35.37)$ & $96(39.01)$ \\
\hline \multicolumn{6}{|l|}{ External environment } \\
\hline $\begin{array}{l}\text { ICPI. DCP has been widely used for early diagnosis of hepatocellular } \\
\text { carcinoma in the medical industry }\end{array}$ & $10(4.07)$ & $6(2.44)$ & $66(26.83)$ & $78(3 \mid .7 I)$ & $86(34.95)$ \\
\hline $\begin{array}{l}\text { ICP2. Many surrounding hospitals are using DCP for early diagnosis of } \\
\text { hepatocellular carcinoma }\end{array}$ & $14(5.69)$ & $20(8.13)$ & $88(35.77)$ & $61(24.80)$ & $63(25.6 I)$ \\
\hline $\begin{array}{l}\text { ICP3. Our business partners recommend DCP for early diagnosis of } \\
\text { hepatocellular carcinoma }\end{array}$ & $7(2.85)$ & $9(3.66)$ & $84(34.15)$ & $74(30.07)$ & $72(29.27)$ \\
\hline $\begin{array}{l}\text { ICP4. The application of DCP in the early diagnosis of hepatocellular } \\
\text { carcinoma has become routinized. }\end{array}$ & $7(2.85)$ & $10(4.07)$ & $86(34.95)$ & $68(27.64)$ & $75(30.49)$ \\
\hline
\end{tabular}

Abbreviations: DCP, des-gamma-carboxy prothrombin; ATT, attitudes; SN, subjective norms; PBC, perceived behavioral control; EOU, ease of use; PR, price rationality; OC, organization culture; TAW, technology absorptive willingness; TSW, technology sharing willingness; ICP, industry competition pressure.

provided as a scientific tool for investigating the mechanism and further promote health technology diffusion in the ICS.

By analyzing the internal consistency and dimensionality of the DHTDICS, the reliability and validity of this instrument have been confirmed. Results of reliability analysis revealed excellent internal consistency, as the value of Cronbach's alpha all greater than 0.80 for four of the domains in this study. Regarding the validity test, EFA results showed all items in each dimension were loaded to four different factors, which fits well with the proposed framework and indicates good construct validity. CFA results showed AVE and CR values of all factors were above the recommended value of 0.5 and 0.7, which indicated an acceptable convergent validity. Additionally, it demonstrated items of the same dimension converged on the same factor, and discriminate well with other factors.
With respect to the potential domains and dimensions that DHTDICS contributes, the results highlighted the definite existence of 4 domains and 9 dimensions: domain of personal beliefs (individuals' perceptions and impressions on subjective and interpersonal predisposition, including dimensions of attitudes, subjective norms and perceived behavioral control), domain of technical drivers (characteristics of health technology on hardware predisposition, including dimensions of ease of use and price rationality), domain of organizational readiness (context preparedness in spiritual level, including dimensions of organizational culture, technology absorptive willingness and technology sharing willingness) and domain of external environment (the forces that can exert influence on physicians from the outside of the hospitals, including dimension of industry competition pressure), which were in line with assumption of scale design and also consistent with the findings of previous research on health 
Table 3 Reliability and Convergent Validity

\begin{tabular}{|c|c|c|c|c|c|c|}
\hline Items & Cronbach's Alpha & $\begin{array}{l}\text { Corrected Item-Total } \\
\text { Correlation }\end{array}$ & $\begin{array}{l}\text { Cronbach's Alpha } \\
\text { if Item Deleted }\end{array}$ & Factor Loadings & AVE & CR \\
\hline ATTI & \multirow[t]{9}{*}{0.960} & 0.846 & 0.954 & 0.918 & \multirow[t]{9}{*}{0.855} & \multirow[t]{9}{*}{0.981} \\
\hline ATT2 & & 0.853 & 0.954 & 0.906 & & \\
\hline ATT3 & & 0.901 & 0.952 & 0.944 & & \\
\hline SNI & & 0.852 & 0.954 & 0.925 & & \\
\hline SN2 & & 0.812 & 0.956 & 0.942 & & \\
\hline SN3 & & 0.843 & 0.954 & 0.935 & & \\
\hline $\mathrm{PBCl}$ & & 0.762 & 0.958 & 0.846 & & \\
\hline PBC2 & & 0.829 & 0.955 & 0.954 & & \\
\hline $\mathrm{PBC} 3$ & & 0.823 & 0.955 & 0.946 & & \\
\hline EOUI & \multirow[t]{6}{*}{0.912} & 0.708 & 0.904 & 0.781 & \multirow[t]{6}{*}{0.736} & \multirow[t]{6}{*}{0.943} \\
\hline EOU2 & & 0.771 & 0.894 & 0.879 & & \\
\hline EOU3 & & 0.736 & 0.899 & 0.864 & & \\
\hline PRI & & 0.740 & 0.899 & 0.853 & & \\
\hline PR2 & & 0.768 & 0.894 & 0.900 & & \\
\hline PR3 & & 0.814 & 0.887 & 0.864 & & \\
\hline $\mathrm{OCl}$ & \multirow[t]{9}{*}{0.957} & 0.790 & 0.954 & 0.864 & \multirow[t]{9}{*}{0.865} & \multirow[t]{9}{*}{0.983} \\
\hline OC2 & & 0.855 & 0.951 & 0.946 & & \\
\hline OC3 & & 0.864 & 0.950 & 0.950 & & \\
\hline TAWI & & 0.776 & 0.955 & 0.902 & & \\
\hline TAW2 & & 0.744 & 0.957 & 0.936 & & \\
\hline TAW3 & & 0.749 & 0.956 & 0.866 & & \\
\hline TSWI & & 0.898 & 0.949 & 0.959 & & \\
\hline TSW2 & & 0.896 & 0.949 & 0.974 & & \\
\hline TSW3 & & 0.897 & 0.949 & 0.966 & & \\
\hline ICPI & \multirow[t]{4}{*}{0.899} & 0.747 & 0.879 & 0.791 & \multirow[t]{4}{*}{0.698} & \multirow[t]{4}{*}{0.902} \\
\hline ICP2 & & 0.718 & 0.892 & 0.756 & & \\
\hline ICP3 & & 0.812 & 0.856 & 0.888 & & \\
\hline ICP4 & & 0.829 & 0.849 & 0.898 & & \\
\hline The whole questionnaire & 0.957 & N/A & N/A & N/A & 0.810 & 0.992 \\
\hline
\end{tabular}

Note: N/A, not applicable.

Abbreviations: AVE, average variance extracted; CR, composite reliability; ATT, attitudes; SN, subjective norms; PBC, perceived behavioral control; EOU, ease of use; PR, price rationality; OC, organization culture; TAW, technology absorptive willingness; TSW, technology sharing willingness; ICP, industry competition pressure.

technology utilization. ${ }^{57-59}$ This result reminded us that successful technology diffusion does not depend solely on the technology itself, individual practitioners, the promotion of organizations, or the external environment, but it is the outcome of the joint efforts of all the aspects mentioned above. It emphasized the importance of taking 
Table 4 Rotated Factor Matrix

\begin{tabular}{|c|c|c|c|c|}
\hline \multirow[t]{2}{*}{ Items } & \multicolumn{4}{|c|}{ Factors and Loadings } \\
\hline & Factor I & Factor 2 & Factor 3 & Factor 4 \\
\hline ATTI & 0.838 & & & \\
\hline ATT2 & 0.874 & & & \\
\hline ATT3 & 0.874 & & & \\
\hline SNI & 0.837 & & & \\
\hline SN2 & 0.809 & & & \\
\hline SN3 & 0.833 & & & \\
\hline $\mathrm{PBCl}$ & 0.730 & & & \\
\hline $\mathrm{PBC} 2$ & 0.753 & & & \\
\hline $\mathrm{PBC} 3$ & 0.743 & & & \\
\hline EOUI & & & 0.613 & \\
\hline EOU2 & & & 0.646 & \\
\hline EOU3 & 0.555 & & 0.586 & \\
\hline PRI & & & 0.792 & \\
\hline PR2 & & & 0.768 & \\
\hline PR3 & & & 0.783 & \\
\hline $\mathrm{OCl}$ & & 0.809 & & \\
\hline $\mathrm{OC2}$ & & 0.879 & & \\
\hline OC3 & & 0.883 & & \\
\hline TAWI & & 0.763 & & \\
\hline TAW2 & & 0.744 & & \\
\hline TAW3 & & 0.726 & & \\
\hline TSWI & & 0.900 & & \\
\hline TSW2 & & 0.893 & & \\
\hline TSW3 & & 0.890 & & \\
\hline ICPI & & & & 0.749 \\
\hline ICP2 & & & & 0.736 \\
\hline $\mathrm{ICP} 3$ & & & & 0.721 \\
\hline ICP4 & & & & 0.725 \\
\hline
\end{tabular}

Notes: Factor I "personal beliefs", Factor 2 "organizational readiness", Factor 3 "technical drivers", and Factor 4 "external environment".

Abbreviations: ATT, attitudes; SN, subjective norms; PBC, perceived behavioral control; EOU, ease of use; PR, price rationality; OC, organization culture; TAW, technology absorptive willingness; TSW, technology sharing willingness; ICP, industry competition pressure.

concrete measures from a multi-dimensional perspective to integrate the efforts of all involved parties while promoting health technology diffusion in the context of ICS.
Table 5 Pearson Correlation Matrix for the Items and the Factors (Bold Values Indicate the Items of the Same Dimension Converge on the Same Factor)

\begin{tabular}{|c|c|c|c|c|}
\hline & Factor I & Factor 2 & Factor 3 & Factor 4 \\
\hline ATTI & $0.838 * *$ & $0.129 *$ & $0.169 * *$ & $0.176 * *$ \\
\hline ATT2 & $0.874 * *$ & 0.101 & 0.106 & $0.130 *$ \\
\hline АТT3 & $0.874 * *$ & $0.163^{*}$ & $0.203 * *$ & $0.155^{*}$ \\
\hline SNI & $0.837^{* *}$ & $0.147 *$ & $0.185 * *$ & $0.151 *$ \\
\hline SN2 & $0.809^{* *}$ & $0.190 * *$ & $0.131 *$ & $0.135 *$ \\
\hline SN3 & $0.833^{* *}$ & $0.126 *$ & $0.154 *$ & $0.169 * *$ \\
\hline $\mathrm{PBCl}$ & $0.730 * *$ & $0.211 * *$ & $0.296 * *$ & 0.060 \\
\hline PBC2 & $0.753^{* *}$ & $0.194 * *$ & $0.361 * *$ & $0.182 * *$ \\
\hline PBC3 & $0.743 * *$ & $0.227 * *$ & $0.388^{* * *}$ & $0.156^{*}$ \\
\hline EOUI & $0.309 * *$ & $0.140 *$ & $0.613^{* * *}$ & $0.319 * *$ \\
\hline EOU2 & $0.461 * *$ & 0.069 & $0.646 * *$ & $0.259 * *$ \\
\hline EOU3 & $0.555 * *$ & $0.139 *$ & $0.586 * *$ & $0.205 * *$ \\
\hline PRI & $0.154 *$ & $0.200 * *$ & $0.792 * *$ & $0.236 * *$ \\
\hline PR2 & $0.253^{* *}$ & $0.191 * *$ & $0.768^{* * *}$ & $0.260 * *$ \\
\hline PR3 & $0.319 * *$ & $0.180 * *$ & $0.783 * *$ & $0.202 * *$ \\
\hline $\mathrm{OCl}$ & $0.223 * *$ & $0.809 * *$ & $0.188^{* * *}$ & 0.000 \\
\hline OC2 & $0.245 * *$ & $0.879 * *$ & 0.104 & -0.012 \\
\hline OC3 & $0.214 * *$ & $0.883^{* *}$ & $0.140 *$ & 0.004 \\
\hline TAll & 0.043 & $0.763^{* *}$ & 0.053 & $0.371 * *$ \\
\hline TAI2 & -0.050 & $0.744^{* *}$ & 0.089 & $0.361 * *$ \\
\hline TAl3 & -0.040 & $0.726^{* * *}$ & $0.210 * *$ & $0.382^{* *}$ \\
\hline TSII & $0.222^{* *}$ & $0.900^{* * *}$ & 0.086 & 0.097 \\
\hline TSI2 & 0.261 ** & $0.893 * *$ & 0.115 & 0.065 \\
\hline TSI3 & $0.239 * *$ & $0.890^{* * *}$ & $0.150 *$ & 0.075 \\
\hline ICPI & $0.283^{* *}$ & $0.153^{*}$ & $0.254 * *$ & $0.749 * *$ \\
\hline ICP2 & $0.156 *$ & $0.170 * *$ & $0.355^{* * *}$ & $0.736 * *$ \\
\hline ICP3 & $0.283^{* *}$ & $0.214 * *$ & $0.331 * *$ & $0.72 I^{* *}$ \\
\hline ICP4 & $0.347^{* *}$ & $0.167 * *$ & $0.284 * *$ & $0.725 * *$ \\
\hline
\end{tabular}

Notes: Factor I "personal beliefs", Factor 2 "organizational readiness", Factor 3 "technical drivers", and Factor 4 "external environment"; Bold values indicate the items of the same dimension converge on the same factor; ${ }^{* *} p<0.01$, ${ }^{*} p<0.05$.

Abbreviations: AVE, average variance extracted; CR, composite reliability; ATT, attitudes; SN, subjective norms; PBC, perceived behavioral control; EOU, ease of use; PR, price rationality; OC, organization culture; TAW, technology absorptive willingness; TSW, technology sharing willingness; ICP, industry competition pressure.

Among multiple domains of the dynamics of health technology diffusion, domains of personal beliefs and organizational readiness were illustrated as two of the 
Table 6 Discriminant Validity (Bold Values in the Diagonal Indicate the Square Root of AVE of the Corresponding Factor)

\begin{tabular}{|l|l|l|l|l|}
\hline & Factor I & Factor 2 & Factor 3 & Factor 4 \\
\hline Factor I & $\mathbf{0 . 9 4 5}$ & & & \\
\hline Factor 2 & $0.465^{* * *}$ & $\mathbf{0 . 9 3 5}$ & & \\
\hline Factor 3 & $0.799^{* * * *}$ & $0.440^{* * *}$ & $\mathbf{0 . 8 5 8}$ & \\
\hline Factor 4 & $0.600^{* * *}$ & $0.436^{* * *}$ & $0.778^{* * *}$ & $\mathbf{0 . 8 6 4}$ \\
\hline
\end{tabular}

Notes: Factor I "personal beliefs", Factor 2 "organizational readiness", Factor 3 "technical drivers", and Factor 4 "external environment"; Bold values in the diagonal indicate the square root of AVE of the corresponding factor; $* * * p<0.001$.

most powerful domains in the DHTDICS in this study, which implied that more attention should be paid to these two aspects. For instance, the domain of personal beliefs, namely Factor 1 in this study, revealed three contributors of positive attitudes, strong subjective norms, and perceived behavioral control. Similarly, the domain of organizational readiness, namely Factor 2 in this research, consisted of organizational culture, the willingness of technology absorptive, and technology sharing, highlighted the importance of developing an organizational atmosphere that advocates technology innovation and promotes interorganizational technology exchange and cooperation. Thus, to promote the diffusion of some appropriate health technology in the RMC, it is recommended to uptake some continuing education and training to raise the awareness of certain health technology and the importance of expanding its use. ${ }^{60}$ Besides, the positive role of subjective norms also highlighted the impact of peer and organization as mentioned above. ${ }^{61}$ As confirmed by previous researches, organizational norms and values control the way individuals interact with each other within or outside the boundaries of the organization. ${ }^{28,29}$ Apart from these domains, the domains of technical drivers and external environment were also significant dynamics components that cannot be ignored in health technology diffusion in the RMC.

This study was strengthened by some features. Firstly, the research model was developed by integrating several previous theories of the IDT, TPB, TAM, TOE, which can combine the strengths of different theories and provide a comprehensive insight into health technology diffusion. Secondly, the findings expanded the knowledge of physicians' DCP use, it will not only directly guide the practice of promoting the utilization of DCP test, but also provide clues for the diffusion of other health technologies in the RMC. Thirdly, the joint application of EFA and CFA ensured the effectiveness and robustness of the results.
However, there are also some limitations to this study. Firstly, due to the effect of social desirability, the participants may not tend to voice negative assessment on the actual performance of themselves and the hospitals, which probably lead to overestimation of the responses. Secondly, owing to time and funding constraints, the DHTDICS has only been validated with a specific technology. The generalizability of this instrument needs to be further validated with other technologies. Thirdly, testretest reliability has not been assessed as the second wave of data collection was not conducted, which may need to be confirmed in future research.

\section{Conclusion}

Under the guidance of multiple theories, this study developed a scale on DHTDICS with the domains of personal beliefs, technical drivers, organizational readiness and external environment. By the agency of calculating Cronbach's alpha and applying EFA and CFA, the reliability and validity of the scale were confirmed, and the roles of the four domains in the DHTDICS were also identified. By providing a robust tool for evaluating the dynamics of health technology diffusion in the RMC, this study will contribute to the knowledge of health technology diffusion in the ICS, and will also benefit to tailor future intervention strategies to promote the effective diffusion and allocation of health technology resources.

\section{Abbreviations}

ICS, integrated care system; PCTs, primary care trusts; PCMH, patient-centered medical home; PCIHC, peoplecentered and integrated health care services; RMC, regional medical consortium; DCP, Des-gamma-Carboxy Prothrombin; PHCC, primary hepatocellular carcinoma; IDT, Innovation Diffusion Theory; TPB, Theory of Planned Behavior; TAM, Technology Acceptance Model; TOE, Technology-Organization-Environment framework; DHTDICS, dynamics of health technology diffusion in integrated care system; ATT, attitudes; SN, subjective norms; PBC, perceived behavioral control; EOU, ease of use; PR, price rationality; OC, organization culture; TAW, technology absorptive willingness; TSW, technology sharing willingness; ICP, industry competition pressure; CITC, corrected item-total correlation; EFA, exploratory factor analysis; PCA, principal components analysis; KMO, Kaiser-Meyer-Olkin; CFA, confirmatory factor analysis; SEM, structural equation 
modeling; AVE, average variance extracted; CR, composite reliability.

\section{Ethical Statement}

Ethical permission was granted for this study from the Ethics Committee of Fujian Medical University (No. 2017-17). This study was conducted under the Declaration of Helsinki. A formal letter of cooperation was written to the directors of each selected medical institution and permission was obtained. All participants were informed about the study purpose, participation in the study was voluntary, and all responses were anonymous. If the participants completed and returned the questionnaire, it was considered informed consent.

\section{Consent for Publication}

All participants provided written informed consent to publish this study.

\section{Acknowledgments}

We acknowledge the support of each hospital for their involvement in this study, as well as all facilitators who contributed to coordination in the site. We also like to thank all physicians who agreed to participate.

\section{Funding}

This research was supported by the National Natural Science Foundation of China (Grant Number: 71704026) and the Distinguished Young Scientific Research Talents Plan in Universities of Fujian Province (Grant number: 2018B030). And the funders had no involvement in study design, data collection, statistical analysis, and manuscript writing.

\section{Disclosure}

The authors declare that they have no conflicts of interest for this work.

\section{References}

1. Gröne O, Garcia-Barbero M; WHO European Office for Integrated Health Care Services. Integrated care: a position paper of the WHO European Office for Integrated Health Care Services. Int J Integr Care. 2001;1:e21. doi:10.5334/ijic.28

2. Nooteboom L, Mulder E, Kuiper C, Vermeiren R. Towards integrated care in the Dutch Youth Care system: an action based research. Int J Integr Care. 2019;19:1-2. doi:10.5334/ijic.s3152

3. Kodner DL. Beyond care management: the logic and promise of vertically integrated systems of care for the frail elderly. In: Knapp M, Challis D, Fernández J, Netten A, editors. Long-Term Care: Matching Resources and Needs. London: Routledge; 2018:101-117.
4. Filliettaz SS, Berchtold P, Kohler D, Peytremann BI. Integrated care in Switzerland: results from the first nationwide survey. Health Policy (New York). 2018;122:568-576. doi:10.1016/j.healthpol.2018.03.006

5. Xu J, Pan R, Pong RW, Miao Y, Qian D. Different models of hospital-community health centre collaboration in selected cities in China: a cross-sectional comparative study. Int $J$ Integr Care. 2016;16:8. doi:10.5334/ijic.2456

6. Sun BX, Zhang RH, Chen Y, He SC. [Development and challenges of current medical consortium in China]. Med Philos. 2015;36:45-46. Chinese.

7. Liang J, Zheng X, Chen Z, et al. The experience and challenges of healthcare-reform-driven medical consortia and Regional Health Information Technologies in China: a longitudinal study. Int $J$ Med Inform. 2019;131:103954. doi:10.1016/j.ijmedinf.2019.103954

8. Song H, Zuo X, Cui C, Meng K. The willingness of patients to make the first visit to primary care institutions and its influencing factors in Beijing medical alliances: a comparative study of Beijing's medical resource-rich and scarce regions. BMC Health Serv Res. 2019;19:361. doi:10.1186/s12913-019-4184-0

9. Integrated care for older people: realigning primary health care to respond to population ageing [homepage on the Internet]. Geneva: World Health Organization; 2018. Available from: https://apps.who. int/iris/handle/10665/326295. Accessed October 1, 2020.

10. Kao WY, Chao Y, Chang CC, et al. Prognosis of early-stage hepatocellular carcinoma: the clinical implications of substages of Barcelona Clinic Liver Cancer System based on a cohort of 1265 patients. Medicine. 2015;94:e1929. doi:10.1097/MD.0000000000 001929

11. Ji J, Wang H, Li Y, et al. Diagnostic evaluation of des-gammacarboxy prothrombin versus $\alpha$-fetoprotein for hepatitis B virusrelated hepatocellular carcinoma in China: a large-scale, multicentre study. PLoS One. 2016;11:e0153227. doi:10.1371/journal.pone. 0153227

12. Sultanik P, Ginguay A, Vandame J, et al. Diagnostic accuracy of desgamma-carboxy prothrombin for hepatocellular carcinoma in a French cohort using the Lumipulse ${ }^{\circledR}$ G600 analyzer. $J$ Viral Hepat. 2017;24:80-85. doi:10.1111/jvh.12622

13. Li Y, Chen J. Serum Des-gamma-carboxy prothrombin for diagnosis of adult primary cancer in liver. J Coll Physicians Surg Pak. 2019;29:972-976. doi:10.29271/jcpsp.2019.10.972

14. Tsuchiya N, Sawada Y, Endo I, Saito K, Uemura Y, Nakatsura T. Biomarkers for the early diagnosis of hepatocellular carcinoma. World J Gastroenterol. 2015;21:10573-10583. doi:10.3748/wjg.v21. i37.10573

15. Song P, Feng X, Inagaki Y, et al. Japan-China Joint Team for Medical Research and Cooperation on HCC. Clinical utility of simultaneous measurement of alpha-fetoprotein and des- $\gamma$-carboxy prothrombin for diagnosis of patients with hepatocellular carcinoma in China: a multicenter case-controlled study of 1,153 subjects. Biosci Trends. 2014;8:266-273. doi:10.5582/bst.2014.01116

16. Tateishi R, Uchino K, Fujiwara N, et al. A nationwide survey on nonB, non-C hepatocellular carcinoma in Japan: 2011-2015 update. J Gastroenterol. 2019;54:367-376. doi:10.1007/s00535-018-1532-5

17. Que Z. The clinical value of combined detection of GGT, AFU, DCP and AFP in diagnosis of hepatocarcinoma. Chin J Prim Med Pharm. 2015;5:743-745.

18. Song P, Feng X, Zhang K, et al. Screening for and surveillance of high-risk patients with HBV-related chronic liver disease: promoting the early detection of hepatocellular carcinoma in China. Biosci Trends. 2013;7:1-6.

19. BenYishay A, Jones M, Kondylis F, Mushfiq AM. Gender gaps in technology diffusion. J Dev Econ. 2020;143:102380. doi:10.1016/j. jdeveco.2019.102380

20. Willis J. Technology diffusion in the "soft disciplines": using social technology to support information technology. Comput Schools. 1992;1:81-106. doi:10.1300/J025v09n01_07 
21. Agha L, Molitor D. The local influence of pioneer investigators on technology adoption: evidence from new cancer drugs. Rev Econ Stat. 2018;1:29-44. doi:10.1162/REST_a_00670

22. Rogers EM. Diffusion of Innovations. New York: Simon and Schuster; 2010.

23. Ajzen I. The theory of planned behavior. Organ Behav Hum Decis Process. 1991;50:179-211. doi:10.1016/0749-5978(91)90020-T

24. Davis FD. Perceived usefulness, perceived ease of use, and user acceptance of information technology. MIS Q. 1989;13:319-340. doi: $10.2307 / 249008$

25. Rogers EM. Diffusion of Innovations. New York: Simon and Schuster; 1995.

26. Tornatzky LG, Fleischer M. Processes of Technological Innovation. David AT, ed. Massachusetts: Lexington books; 1990.

27. Ross J, Stevenson F, Lau R, Murray E. Factors that influence the implementation of e-health: a systematic review of systematic reviews (an update). Implement Sci. 2016;11:146. doi:10.1186/ s13012-016-0510-7

28. Weir NM, Newham R, Dunlop E, Bennie M. Factors influencing national implementation of innovations within community pharmacy: a systematic review applying the Consolidated Framework for Implementation Research. Implement Sci. 2019;14(1):21. doi:10.1186/s13012-019-0867-5

29. Felgner S, Ex P, Henschke C. Physicians' decision making on adoption of new technologies and role of coverage with evidence development: a qualitative study. Value Health. 2018;21:1069-1076. doi:10.1016/j.jval.2018.03.006

30. Balas EA, Chapman WW. Road map for diffusion of innovation in health care. Health Aff. 2018;37:198-204. doi:10.1377/hlthaff.2017.1155

31. Paré G, Sicotte C, Poba-Nzaou P, Balouzakis G. Clinicians' perceptions of organizational readiness for change in the context of clinical information system projects: insights from two cross-sectional surveys. Implement Sci. 2011;6:15. doi:10.1186/1748-5908-6-15

32. Wilcock M, Harding G. What do pharmacists think of MURs and do they change prescribed medication? Pharm J. 2008;281:163-167.

33. Kummer TF, Recker J, Bick M. Technology-induced anxiety: manifestations, cultural influences, and its effect on the adoption of sensor-based technology in German and Australian hospitals. Inform Manage. 2017;54:73-89. doi:10.1016/j.im.2016.04.002

34. Blank JLT, Valdmanis VG. Technology diffusion in hospitals: a log odds random effects regression model. Int $J$ Health Plann Manage. 2015;30:246-259. doi:10.1002/hpm.2232

35. Kim KK, Sankar P, Wilson MD, Haynes SC. Factors affecting willingness to share electronic health data among California consumers. BMC Med Ethics. 2017;18:25. doi:10.1186/s12910-017-0185-x

36. Weitzman ER, Kelemen S, Kaci L, Mandl KD. Willingness to share personal health record data for care improvement and public health: a survey of experienced personal health record users. BMC Med Inform Decis Mak. 2012;12:39. doi:10.1186/1472-6947-12-39

37. Wang BB, Wan TTH, Burke DE, Bazzoli GJ, Lin BYJ. Factors influencing health information system adoption in American hospitals. Health Care Manage Rev. 2005;30:44-51. doi:10.1097/ 00004010-200501000-00007

38. Liu CF. Key factors influencing the intention of telecare adoption: an institutional perspective. Telemed J E Health. 2011;17:288-293. doi:10.1089/tmj.2010.0184

39. Benavides VS, Strode A, Sheeran BC. Using technology in the delivery of mental health and substance abuse treatment in rural communities: a review. J Behav Health Serv Res. 2013;40:111-120. doi:10.1007/s11414-012-9299-6

40. Sun KX, Zheng RS, Zhang SW, et al. Report of cancer incidence and mortality in different areas of China, 2015]. China Cancer. 2019;28 (01):4-14. Chinese.

41. Zhou Y, Ma JY, Jiang HJ, Lin YT. [Analysis of cancer incidence and mortality in Fujian cancer registries, 2014]. Chin J Clin Oncol. 2018;45(17):898-903. Chinese.
42. Liu J, Zhu LP, Yang XL, Xu Y, Yan W, Chen YY. [Incidence, mortality and life lost of malignancies among residents living in areas covered by cancer registry in Jiangxi province, 2010-2017]. Chin J Public Health. 2018;34(12):1692-1695. Chinese.

43. Nunnally JC. Psychometric Theory. 2nd ed. New York: McGraw-Hill; 1978.

44. Ahmad MH, Ibrahim MI, Rahman AA, et al. Development and validation of positive smoker identity questionnaire (PSmoQi): a new instrument for smoking cessation correlates. Int J Environ Res Public Health. 2019;16:351. doi:10.3390/ ijerph16030351

45. Gefen D, Straub DW, Boudreau MC. Structural equation modeling and regression: guidelines for research practice. Commun Assoc Inf Syst. 1978;4:1-70.

46. Gorusch RL. Factor Analysis. 2nd ed. Hillsdale: Lawrence Erlbaum Associates; 1983.

47. Fornell C, Larcker DF. Evaluating structural equation models with unobservable variables and measurement error. J Mark Res. 1981;18:39-50. doi:10.1177/002224378101800104

48. Bagozzi RP, Yi Y. On the evaluation of structure equation models. J Acad Mark Sci. 1998;16:74-94. doi:10.1007/BF02723327

49. Kaiser HF. An index of factorial simplicity. Psychometrika. 1974;39:31-36. doi:10.1007/BF02291575

50. Ramli R, Ali N, Teleconsultation as knowledge management system: recognizing the issues contributing to its underutilization in hospitals. Proceedings of the 2018 International Conference on Advanced Computer Science and Information Systems (ICACSIS); 2018 Oct 27-28; Yogyakarta, Indonesia, New York: IEEE.

51. Coughlin JM, Zang Y, Terranella S, et al. Understanding barriers to lung cancer screening in primary care. J Thorac Dis. 2020;12 (5):2536-2544. doi:10.21037/jtd.2020.03.66

52. Dulai GS, Farmer MM, Ganz PA, et al. Primary care provider perceptions of barriers to and facilitators of colorectal cancer screening in a managed care setting. Cancer. 2010;100(9):1843-1852. doi:10.1002/cncr.20209

53. Hudson PS, Ana LDV. Health technology diffusion in developing countries: a case study of CT scanners in Brazil. Health Policy Plann. 2018;26(5):385-394.

54. Wani D, Malhotra M. Does the meaningful use of electronic health records improve patient outcomes? J Oper Manage. 2018;60:1-18. doi:10.1016/j.jom.2018.06.003

55. Elnahal SM, Peabody H, Ippolito A, Littlefield P, Clancy C, Shulkin D. Diffusing oncology care model best practices across America's largest integrated hospital system. Int J Radiat Oncol. 2016;96:E397-E398. doi:10.1016/j.ijrobp.2016.06.1630

56. Saini V, Brownlee S, Elshaug AG, Glasziou P, Heath I. Addressing overuse and underuse around the world. Lancet. 2017;390 (10090):105-107. doi:10.1016/S0140-6736(16)32573-9

57. Weiner BJ. A theory of organizational readiness for change. Implement Sci. 2009;4:67. doi:10.1186/1748-5908-4-67

58. Eby LT, Adams DM, Russell JEA, Gabe SH. Perceptions of organizational readiness for change: factors related to employees' reactions to the implementation of team-based selling. Hum Relat. 2000;53:419-442. doi:10.1177/0018726700533006

59. Holt DT, Helfrich CD, Hall CG, Weiner BJ. Are you ready? How health professionals can comprehensively conceptualize readiness for change. J Gen Intern Med. 2010;25:50-55. doi:10.1007/ s11606-009-1112-8

60. Liu C, Liu C, Wang D, Zhang X. Intrinsic and external determinants of antibiotic prescribing: a multi-level path analysis of primary care prescriptions in Hubei, China. Antimicrob Resist Infect Control. 2019;8:132. doi:10.1186/s13756-019-0592-5

61. Young HP. The evolution of social norms. Ann Rev Econ. 2015;7:359-387. doi:10.1146/annurev-economics-080614-115322 


\section{Publish your work in this journal}

Risk Management and Healthcare Policy is an international, peerreviewed, open access journal focusing on all aspects of public health, policy, and preventative measures to promote good health and improve morbidity and mortality in the population. The journal welcomes submitted papers covering original research, basic science, clinical \& epidemiological studies, reviews and evaluations, guidelines, expert opinion and commentary, case reports and extended reports. The manuscript management system is completely online and includes a very quick and fair peer-review system, which is all easy to use. Visit http://www.dovepress.com/testimonials.php to read real quotes from published authors. 